\title{
CONCEPTUALISING RISK IN DOCTORAL EDUCATION
}

\author{
NAVIGATING BOUNDARY TENSIONS
}

\section{Liezel Frick, Ruth Albertyn and Eli Bitzer}

\section{INTRODUCING RISK}

If you are not willing to risk the unusual, you will have to settle for the ordinary. - Jim Rohn

Risk-taking is an important form of human behaviour, but can be conceptualised in different ways (Byrnes, Miller \& Schafer 1999). Some researchers in higher education point to the association between academic risk and its negative consequences (McWilliam, Lawson, Evans \& Taylor 2005; McWilliam, Sanderson, Evans, Lawson \& Taylor 2006; McWilliam, Singh \& Taylor 2002) and therefore conceptualise risk as something that should be avoided or at least carefully managed. Others highlight risk as an opportunity for achievement (Backhouse 2009; Frick 2011, 2012; Holligan 2005). If innovation is key to the generation of new knowledge, then risk is seen to be an integral part of this process (Brown 2010). Knowledge and innovation are considered to be critical contributors to national wealth and welfare and therefore doctoral education has gained increasing significance within the context of human capital development (Bloland 2005; CHE 2009). In this context, the dynamics of balancing risk and innovation (Brown 2010; Latham \& Braun 2009) may provide challenges for the supervisory relationship and the research process. Education and more specifically doctoral education - seems to be risky given the requirement to produce original knowledge. Students need to have "the courage and confidence to take risks, to make mistakes, to invent and reinvent knowledge, and to pursue critical and lifelong inquiries in the world, with the world, and with each other" (Freire 1970, cited in Lin \& Cranton 2005:458). MacKinnon (1970) agrees that the courage to take risks is an important characteristic of creative endeavours - such as doctoral studies. In this chapter we therefore take the position that risk is unavoidable within the context of doctoral education, but in order to extend the boundaries and 
manage risk constructively, supervisors could gain from understanding the concept of risk within this context.

This chapter takes up the question of risk in doctoral education with a particular focus on a number of ways in which the concept of risk currently operates in doctoral education. The discussion draws from a broad understanding of risk in doctoral education and the concept of risk in general, as well as a small-scale study with experienced doctoral supervisors across disciplines at one South African university. We propose that risk is not an inevitably negative concept which necessarily results in danger. Risk also seems to provide opportunities for increased and higher levels of scholarly performance and results. By identifying tensions and ways of containing risk, the boundaries of doctoral education may be challenged so that postgraduate supervisors may be better equipped to facilitate the process of student development towards an original contribution at a doctoral level. In this sense doctoral supervisors become boundary navigators.

\section{RISK DEFINED}

Risk seems to be a dichotomous concept. Byrnes et al. (1999) argue that risk can be either adaptive or maladaptive. In the latter case the potential hazardous consequences outweigh the potential benefits. Adaptive risk, on the other hand, does not mean avoiding all risk. Instead it refers to adapting successfully though pursuing some risks while avoiding others. Generally risk is defined in terms of risky behaviour with possible negative consequences, but it can also be defined in terms of adaptivity, rationality, and/or the importance of generic versus environmental factors in establishing human traits (Byrnes et al. 1999).

When defining risk in doctoral education there are four aspects that need consideration (based on the work of Byrnes et al. 1999). Firstly, risk is closely associated with goals, values and outcomes. It follows that if the goal is to achieve the outcome of a doctorate in the minimum allocated time, the risk of choosing a complex and less defined problem might be avoided. However, if the original contribution made though a doctoral study is valued, risk-taking may be encouraged. Secondly, risk involves interplay between an individual's subjective perception of risk and the perceptions of the larger community. What is perceived as risky within doctoral research may therefore be interpreted differently by students and their supervisors (who form part of larger institutional and disciplinary communities), and the outcome of such perceptual differences is determined by negotiation and power differences between the parties involved. Thirdly, individual skill determines to what extent actions are deemed as being risky. Thus, a research project may be 
less risky if the doctoral student has research and/or subject expertise. Fourthly, context is cardinal - for example, certain projects may become less risky if expert supervision and other resources are readily available in the doctoral context. It thus appears that the conceptualisation of risk reflects contradictory forces which relate to elements in the context, the relationships in the supervisory process and the outcome of doctoral education.

The context of doctoral education is pivotal as it influences both the processes and the outcomes. McWilliam et al. (2002:120) refer specifically to risk within higher education institutions as a management issue - "a system of rules, formats and technologies for communicating within and across institutions", which is intended to "shape who can take what risks and how" (Hood et al. 1992:136). Institutional emphasis on ethical conduct in research has placed the concept of risk regarding the process and outcome centre stage at higher education institutions. As such the conceptualisation of risk is primarily defined in terms of its potential negative consequences - risk-as-danger (McWilliam et al. 2005) - as is evident in the Framework Policy for the Assurance and Promotion of Ethically Accountable Research at Stellenbosch University that demands that all research be preceded by a thorough risk benefit analysis (SU 2012:2-3). Ethical risks relate primarily to the doctoral topic and project, which highlights "the danger to perform in ways that are morally and politically, as well as organizationally, acceptable" (McWilliam et al. 2005). This implies that risk is a double-edged sword which could cut both institutions and supervisors on the one hand and students on the other in scandalous ways. Thus risks in the core relationship are an added dimension. McWilliam et al. (2002) draw attention to further risks during the doctoral process ranging from coauthorship and plagiarism to 'soft' assessment, while McWilliam et al. $(2005,2006)$ add trivial thesis topics, suspect entry, rigour and assessment requirements, and dubious conduct and/or credentials to the list of possible risks at the doctoral level. Together with Golde (2005), these authors furthermore refer to long completion times and low completion rates (doctoral student dropout and attrition) which are a waste of resources and thus an institutional risk. Evans and Kamler (2003) and Paré (2010) point out the risks involved in doctorates via publication, where too much may be expected of students too soon. Defining risk is therefore not limited to identification of risks, but also to the calculability of risk factors and risk events which may ensue (McWilliam et al. 2006).

The institutionalisation of risk as danger is not surprising given the current worldwide emphasis on auditing and accountability within higher education. Given these definitions of risk, it is to be expected that supervisors' default conceptualisation of 
risk would lean towards a negative perception and thus supervision would be aimed at risk avoidance. There is a danger in what McWilliam et al. (2002) call a negative logic of risk, or risk avoidance (McWilliam et al. 2006), as it is essentially punitive in nature and may erode what Holligan (2005) refers to as scholastic autonomy and organic collegiate communities. Therefore supervisors' conceptualisation of risk is all the more important as supervisory, institutional and disciplinary constraints may impede creativity at the doctoral level and thus also the (expected) original contribution a doctoral student is able to make.

\section{THE RISKY BUSINESS OF DOCTORAL SUPERVISION}

Supervisors play a key role in doctoral students' understanding of the original contribution they are expected to create, and therefore also the extent of risk allowed in their research. Perez-Freije and Enkel (2007) noted tensions amongst team members in a creative endeavour. These authors state that balance is necessary between structured and disciplined operations and flexibility and openness in the approach, which McWilliam et al. (2006) refer to as risk avoidance versus risk mitigation. Delamont, Atkinson and Parry (2004:35) contend that supervision is based on the perceived tension between the need to guide and structure on the one hand, and the desire to preserve the student's autonomy on the other. Previous research (Backhouse 2009; Frick 2011, 2012; Holligan 2005) found that external factors - such as bureaucratic institutional systems, ethics and funding policies - may influence the extent to which risk-taking is possible in doctoral studies. Evans (2004) conceptualises the role of the supervisor as that of risk manager and risk mitigator, acting as an intermediary between the demands of society, the discipline(s) involved, the institution and the doctoral candidate - a position somewhat between a rock and a hard place given the pressures exerted from both sides on the supervisor(s).

Previous studies found that supervisors found it difficult to push knowledge boundaries by means of the postgraduate work they supervise, and took measures to limit risktaking in order to ensure adequate doctoral student throughput and publication (Backhouse 2009; Frick 2011, 2012; Holligan 2005). Backhouse (2009:281) argues that through avoiding risk, supervisors may guide doctoral students away from an "exciting creative journey" towards a "series of cynical strategic choices" and "modest safe projects". By playing it safe, supervisors may actually deprive students of the opportunity to experience the real world of most research which can be messy, unpredictable and complex. Holligan (2005:270) warns that structures and guidelines offer a "mechanistic discourse of support" and may be useful to learn the rules that govern the academic game, but fail to induct novice supervisors 
and doctoral students into knowing how far institutional and disciplinary boundaries can be pushed. Scientific progress depends on pushing such boundaries through independent critical thought - a risky endeavour given the current emphasis on risk management and control (Pearson, Evans \& MacAuley 2008). Both Backhouse (2009) and Frick $(2011,2012)$ argue that supervisors should support risk-taking as they guide doctoral students towards making an original contribution.

Previous studies have, however, not focused on supervisors' perceptions of risk in particular. This chapter explores whether doctoral education involves particular forms of risk for candidates and supervisors, as well as the direction and nature of the risk involved.

\section{RESEARCHING RISK (METHODOLOGY)}

A descriptive exploratory study was undertaken using qualitative data collected through conducting in-depth interviews with 11 purposively selected doctoral level postgraduate supervisors. Selection criteria for participants included context of supervision, discipline, and level of experience. Supervisors represented natural science (3), economics and management sciences (3), health and medicine (1), engineering (1), humanities (1), education (1) and theology (1) at Stellenbosch University (South Africa). In-depth interviews focused on how these supervisors conceptualised risk within doctoral education in their specific contexts. The interview schedule consisted of three guiding questions:

- How do you conceptualise risk in doctoral education?

- In what ways may risk play a role in your discipline in development of the original contribution at a doctoral level?

- How do you manage risk in your work with doctoral students?

Qualitative data analysis of transcriptions of the interviews was done with ATLAS.ti software. An inductive approach to qualitative content analysis was followed, according to the steps suggested by Henning, Van Rensburg and Smit (2004). This process of content analysis involved fine coding the data, categorising the codes and finally, identifying themes. Member checking was done randomly and data analysis was done by two researchers independently. The findings are reported below according to the themes we identified.

\section{FINDING RISK: CONCEPTUALISATIONS OF EXPERIENCED SUPERVISORS}

Experiences of supervisors revealed conceptualisations of risk at different stages in the research process. We report on the risks at each stage of the doctoral research 
process where risk was noted, including preparation and proposal stage, execution of the research plan and concluding the research. The findings relate to the risk at each of these stages and the strategies supervisors employ to support their doctoral students. Thereafter we present the conceptualisations of risk in the system and discuss how these risks influence the student and the supervisor.

\section{Risk in the stages of the postgraduate research process: Preparation and proposal stage}

The crucial preparation stage includes risks associated with conceptualising and planning which culminate in the proposal. Risks link to the type of project (more practice-based and developmental rather than scientific and research-based), unclear conceptualisation of the project, problematic topic selection (personal attachment to the topic, length and scope of the topic) and the nature of the research question. The problem of a poorly conceptualised project is that the risks are exacerbated as the project progresses. Often students in particular fields such as education who enter the system are practitioners: "They are very able people, but they are not academics" (s7). They are students who find it hard to make the transition to research and understanding the nature of the scientific process and the depth and rigour required: "She thinks she is ready to do a doctoral study ... the subject is totally not a topic that you can use for a doctoral study" (s6). Byrnes et al. (1999) also note this type of risk due to differing perspectives. Supervisor 2 suggests that the focus needs to be on asking the student, "What is the intellectual contribution?" rather than the practical contribution of the study.

Often students want to take on complex problems. As supervisor 3 commented: "All the students that we get want to solve the world's problems." There is a risk that students read so widely initially that they battle to focus. This may be due to anxiety and insecurity in the new language of the field as well as being unsure of what constitutes a PhD study. The students may become overwhelmed by the volume of work, so guidance is needed.

Ways of overcoming risk include the prerequisite in some disciplines of having the proposal as a screening strategy to test whether the student has reached the level of clarification of concepts, context and the necessary focus: "You must first do the proposal, first get past the committee" (s6). Students also must retain the focus appropriate for their field of study.

Supervisors are expected to give strong guidance in the preparation stage to ensure that the project does not get too big (s6) and that the topic is relevant and novel so 
that the student can make a unique contribution (s4). Supervisors suggest that it is important not to accept students outside of their scope of expertise or interest (s10). Co-supervisors can be used where needed. Expectations of the requirements of the process, the personal cost to the student and the relationship need to be made clear at the outset. Some students have unrealistic expectations: "... the expectation that I come in here ... I talk to my study leader and my study leader tells me what I should do" (s7). This dependence needs to be broken early in the postgraduate relationship as the student needs to takes ownership of the project and move to independence, especially at the doctoral level. Delamont et al. (2004:35) refer to the need to balance guidance and autonomy in supervision. Supervisor 2 asks the student, "What is the intellectual puzzle that you are proposing to research?" Sometimes this conversation about expectations with students makes them reconsider whether they are ready for the process or not. One supervisor (s2) sets as a proviso that the student read for 18 months in preparation for his or her studies.

The development of a generative relationship between the student and the supervisor was noted by supervisor 2. He "engages with the relationship between the person's identity orientation to a proposed study and moving from there to an intellectual orientation to that study that establishes the intellectual worth of the study". The essence of the support by this supervisor is intellectual grounding as well as contact and dialogue in developing scholarly depth. It may be necessary for the supervisor to find ways of supporting students in this phase when they may be feeling fearful and anxious at the newness of the field. Warhurst (2006:1 18) found learning to be a "painful process of becoming a different kind of person, of reconstructing identity". Clegg, McManus, Smith and Todd (2006:92) claim that the challenges linked to this level of learning are creative and hold the potential for new meaning making that should be valued. Meyer and Land (2005:375) suggest that this level of learning leads to transformed thought, to an identity transfiguration of adopting an extended discourse. A strategy to help students is through exposing them to fellow students who are at various stages in the research process and helping them to develop the language needed for the new field of study (s1). According to supervisor 3 , the group setting helps students think critically as they are challenged by their peers. In the group setting the student develops critical thinking skills early in the process.

\section{Risk in the stages of postgraduate research process: Execution of the research plan}

In the execution stage there are risks related to data collection, analysis and writing up:

The risk of the middle of course is ... that people don't collect data of a sufficient quality. If you have done your data collection with the appropriate rigour, everything falls down. (s11) 
... even though the $\mathrm{PhD}$ students design their own experiment and ask their own question, with input from me, there is always in the back of my mind, what happens if that does not come through? (s8)

There may be risks related to ethical issues (also noted by McWilliam et al. 2005) and access to data. Sometimes the response rate is insufficient and students may need to deviate from their original plan in their proposal. An example of this was noted by supervisor 6: "Then there was such thin superficial data that I had to say I am sorry we cannot go with this ... you need to conduct more interviews or include a focus group ... I did not allow it to go through to examination." Sometimes the response rate is so low that no conclusions can be drawn (s5). An example of risk with analysis is:

And when I started to analyse the data, I came to totally different conclusions. And he did not do it on purpose ... it was a bona fide error ... He had actually got it wrong ... totally wrong. So, that is a risk. (s7)

Momentum is required during this phase of the project. In the data collection phase support is provided with project management skills. Regular meetings to discuss data analysis and provide help in this regard are offered by referring students to experts for assistance (co-supervisors or statisticians). Meeting with peers in colloquia also provides support as group members present sections of their work in this nonthreatening environment. By being involved in dialogue, knowledge is created through "the construction and transformation of understanding through the tension between multiple perspectives and opinions" (Dysthe, Samara \& Westrheim 2006:303). Colloquia encourage momentum and accountability (s5), which in turn helps with motivation (s3) and seems to be a common practice in departments. Supervisor 2 offers another strategy for maintaining momentum:

[W] hat I am committed to, is to establish a process individually with them and $\ldots$ in a collective process, so that they feed off each other ... I don't meet with them unless they give me 1-4 pages of writing ... So I establish momentum as well and I can engage with the writing much better. I establish a routine. I establish habits. (s2)

He also tries to give feedback within seven days to keep up the momentum. Supervisor 5 also emphasises the importance of momentum and notes that if students start procrastinating it is a sign that they have lost momentum. He will adopt an empowering approach and tries to engage such students and talk through the problem. If students are hesitant he will try to give direction.

In keeping the student on track and providing momentum, supervisor 8 tries to counter isolation: 
... take a group of students to their site to help them, and that also always boosts them, so the risk there is the isolation ... because what happens in the group when one hits a low, there is another one that is on a high and they ride the wave with the one on the high, so it balances it out.

... the first-year students coming to the second-year students, passing advice on, techniques, that type of thing. It is like having each one to have ... a buffer between the student and myself, because they say a lot of the times the students are too embarrassed to come and ask me a simple question, about a simple technique.

Support is clearly vital during this stage but could be provided through group processes in addition to supervisor input.

\section{Risk in the stages of the postgraduate research process: Concluding the research}

Risk at the concluding stage includes the review process during the examination and publication process. The examination process poses risks not only to the student, who may be required to do extra work, but also to the supervisor's reputation and credibility, and to the department and the university.

... then a person feels that the supervisor is actually in the firing line together with the student ... so it is a great risk to get the student to the examination. (s6)

There may be hostility at this stage and there is much at stake for all parties: "... the examination process I think ... the more I see it, the more I doubt the fairness of that" (s7). The incorrect choice of examiner can influence the outcome, and problems such as selection of friends, inexperienced examiners, perspective and paradigmatic differences play an important role:

You often don't find somebody who actually fits that bill or they are so overworked, because they get everybody's ... They need to be experts but they also need to deliver. (s 10)

... although the CVs are submitted, supervisors choose their friends ... examiners look at the thesis from their own perspective ... invariably those conclusions are extremely biased. (s7)

There are risks involved prior to sending the dissertation for examination. Students may be tired of the project and want to conclude without the necessary higher conceptualisation having taken place. Students may have financial, personal or work constraints, and the supervisor may be pressurised to allow the project to go for examination to meet a deadline without having checked technical aspects or before it has reached a level of maturity and wisdom: 
... because sometimes if you are rushing a thesis ... you might miss out on that critical kind of incubation period ... that sort of Einstein moment ... You start to see really what it is what you have found and how it connects to each other and the literature and ... then something happens. (s4)

It can take a few months actually to really work on that ... suddenly there is a sort of you start synthesising and connecting ... then somehow there is a sort of magic that happens. (s 11 )

Early submission could influence the outcome and the unique contribution to knowledge required of the doctorate. This is a risk aspect also noted by Byrnes et al. (1999). At this stage the supervisor has a pronounced sense of risk and a decision needs to be made regarding whether to submit the thesis or not.

Supervisors have some suggestions which relate to intellectual development and peer review for monitoring the level of work: "It would be helpful to have an outside view as the supervisor seems to be too close to the project by the end of the process ... a round of quality control ... before the thesis is sent out for examination as they do overseas." (s9) Some supervisors encourage writing for publication as it helps students to conceptualise their work at stages along the way. Students are exposed to peer review, which also contributes to the intellectual development independent thought and integrative thinking:

PhDs are written up in a form of a series of research papers so that the students get exposure to writing in a rigorous scientific style ... The danger there of course is writing a research paper - that is quite a tough thing to do. (s 11 )

I find that if you have a thesis and you can say the following papers have already been published from this work, it sets the standard for the examiner. (s8)

The concluding stage, therefore, is a crucial risk stage which has implications for the system, the supervisor and the student.

\section{Conceptualising risk: Risk as a reciprocal notion}

There are reciprocal risks affecting the context, supervisor and student. The student is seen to be at risk if their level of preparation is unknown to the supervisors especially if students enter the system from a different university with different standards "which is a bit worrying, because you would like to take on external students, but you don't know what their background is in terms of: can they do this?" (s10). Examples of under-preparedness may be inappropriate research methodology or poor academic writing. If the student is underprepared, then the supervisor will be expected to 
provide more input to support the student. The risk to the supervisor is felt regarding their workload and the time it takes to do supervision. Due to the performance management system of the university, the supervisors are expected to supervise regardless of their expertise or desire to perform this task.

Lack of resources is a further risk with ramifications. Many students face financial challenges which jeopardise their progress and completion, so access to funding is vital. There is, however, tension between funded projects and motivation of students, as slotting into a funded project could influence student engagement. This debate varies across disciplines. Even though slotting into existing projects is common practice in the natural sciences, there is the risk of potential lack of engagement:

[I]f it is primarily your interest and not the student's interest, then experience has taught me that the motivation to complete that study dries up relatively quickly ... there should be enough interest to make the student excited ... to complete the process. (s4)

The students' level of motivation is crucial and often the $\mathrm{PhD}$ product as goal is viewed as being a risk factor. "If someone walks in and says he wants to do a PhD and you ask, 'On what?' And he says, 'No, I don't know yet' ... it can't work like that" (s3). Golde (2005) confirms lack of motivation as a reason for non-completion of postgraduate students. Risks for stakeholders therefore relate to preparation, support and resources.

\section{CONCLUSION}

The findings of the interviews with supervisors of doctoral students revealed that there are risks to various stakeholders (the system, student and supervisor) at the different research stages in the research process. The student enters the higher education system and the risks at this point relate to student selection and student preparation (previous research and disciplinary training) as well as resources. The student then engages with a supervisor who has certain levels of experience and expertise. The postgraduate relationship is the interface between the student and the supervisor. The stages of the research process (preparation, execution and conclusion) are conceptualised as the central core risks for these supervisors in their role in doctoral education. Supervisors report various strategies in these stages to support the students and mitigate risk. These can be summarised according to the following typology:

- Student selection: Clear expectations, determining and developing student capability, independence, analytical thinking skills, problem-solving skills, integrative thinking skills, creativity, and expectations 
- Conceptualising: Wide reading, critical debate, benchmarking, time for incubation of ideas, challenging students

- Skill development: Academic writing, research methodological skills, incorporating expert input

- Support: Networking, colloquia, regular contact, communication, co-supervision; mentoring

- Application: Peer review, writing for publication.

Further research could explore innovative ways of balancing rather than controlling risk whilst encouraging creativity in the doctoral education process. The system where performance management is highly visible seems to predispose the supervision of students regardless of the supervisor's expertise and interest. This may lead to mechanistic supervision where control is valued to ensure throughput at an acceptable level rather than creativity which will contribute to knowledge and the expansion of science. Awareness of risk and the link to the positive component of creativity could lead supervisors to contain risk in a responsible manner. In so doing the boundaries of the conceptualising risk in doctoral education can be fruiffully navigated and even extended to ensure that a quality outcome and the original contribution to knowledge are attained in the doctoral process.

\section{REFERENCES}

Backhouse J. 2009. Creativity within limits: Does the South African PhD facilitate creativity in research? Journal of Higher Education in Africa, 7(1/2):265-288.

Bloland HG. 2005. Whatever happened to postmodernism in higher education? No requiem in the new millennium. The Journal of Higher Education, 76(2):121-150.

Brown L. 2010. Balancing risk and innovation to improve social work practice. British Journal of Social Work, 40:121 1-1228.

Byrnes JP, Miller DC \& Schafer WD. 1999. Gender differences in risk taking: A meta-analysis. Psychological Bulletin, 125(3):367-383.

CHE (Council for Higher Education). 2009. Higher Education Monitor No. 7. Postgraduate studies in South Africa: A statistical profile. Pretoria.

Clegg S, McManus M, Smith K \& Todd MJ. 2006. Self-development in support of innovative pedagogies: Peer support using email. International Journal for Academic Development, $11(2): 91-100$.

Delamont S, Atkinson P \& Parry O. 2004. Supervising the doctorate. $2^{\text {nd }}$ edition. Maidenhead: Open University Press.

Dysthe O, Samara A \& Westrheim K. 2006. Multivoiced supervision of master's students: A case study of alternative supervision practices in higher education. Studies in Higher Education, 31 (3):299-318. 
Evans T. 2004. Risky doctorates: Managing doctoral studies in Australia as managing risk. Paper presented at the Australian Association for Research in Education Conference, Melbourne, 28 November - 2 December 2004.

Evans T \& Kamler B. 2003. Theses: For examination not publication? Paper presented at the $4^{\text {th }}$ International Conference on Professional Doctorates, Brisbane, 29-30 November.

Frick BL. 2011 . Demystifying the original contribution: Supervisors' conceptualisations of creativity in doctoral education. Pertanika Journal of Social Sciences, 19(2):495-507.

Frick BL. 2012. Pedagogies for creativity in science doctorates. In: A Lee \& S Danby (eds). Reshaping doctoral education: Programs, pedagogies, curriculum. London: Routledge. $113-127$.

Golde CM. 2005. The role of the department and discipline in doctoral student attrition: Lessons from four departments. Journal of Higher Education, 76(6):669-700.

Henning E, Van Rensburg W \& Smit B. 2004. Finding your way in qualitative research. Pretoria: Van Schaik.

Holligan C. 2005. Fact and fiction: A case history of doctoral supervision. Educational Research, 47(3):267-278.

Hood CC, Jones DKC, Pidgeon NF, Turner BA, Gibson R \& Bevan-Davies C. 1992. Risk management. In: The Royal Society (ed). Risk: Analysis, perception and management. London: The Royal Society. 89-134.

Latham S. \& Braun M. 2009. Closing the loop: Innovation and decline. Academy of Management Annual Meeting, Chicago, IL. August 7-1 1.

Lin L \& Cranton P. 2005. From scholarship student to responsible scholar: A transformative process. Teaching in Higher Education, 10(4):447-459.

Macauley P, Evans T \& Pearson M. 2010. Australian PhDs by LIS educators, researchers and practitioners: Depicting diversity and demise. Library and Information Science Research, 32(4):258-264.

MacKinnon D. 1970. Creativity: A multi-faceted phenomenon. In: JD Roslansky (ed). Creativity. Amsterdam: North-Holland. 19-32.

McWilliam E, Lawson A, Evans T \& Taylor PG. 2005. Silly, soft and otherwise suspect: Doctoral education as risky business. Australian Journal of Education, 49:214-227.

McWilliam E, Sanderson D, Evans T, Lawson A \& Taylor PG. 2006. The risky business of doctoral management. Asia Pacific Journal of Education, 26(2):209-224.

McWilliam E, Singh P \& Taylor PG. 2002. Doctoral education, danger and risk management. Higher Education Research and Development, 21 (2): 1 19-129.

Meyer JHF \& Land R. 2005. Threshold concepts and troublesome knowledge (2): Epistemological considerations and a conceptual framework for teaching and learning. Higher Education, 49:373-388.

Paré A. 2010. Slow the presses: Concerns about premature publication. In: C Aitchison, B Kamler \& A Lee (eds). Publishing pedagogies for the doctorate and beyond. Oxon: Routledge. 30-46. 
Blitzer E, Albertyn R, Frick L, Grant B, Kelly F (eds) 2014. Pushing Boundaries in Postgraduate Supervision. Stellenbosch: SUN PRESS

\section{PART TWO • EXPANSION AND RISK}

Pearson M, Evans T \& MacAuley P. 2008. Growth and diversity in doctoral education: Assessing the Australian experience. Higher Education, 55(3):357-372.

Perez-Freije J \& Enkel E. 2007. Creative tension in the innovation process: How to support the right capabilities. European Management Journal, 25(1):11-24.

SU (Stellenbosch University). 2012. Departmental Ethics Screening Committee (DESC) guidelines. [Accessed 24 July 2012] http://www0.sun.ac.za/research/assets/files/Human_ Research_(Humanities)_Ethics/DESC_Guidelines_Sept2012.pdf

Warhurst, RP. 2006. "We Really Felt Part of Something": Participatory learning among peers within a university teaching development community of practice. International Journal for Academic Development, 11 (2): 11 1-122. 